\title{
Role of cerebral function monitoring in the newborn
}

\author{
L S de Vries, L Hellström-Westas
}

Arch Dis Child Fetal Neonatal Ed 2005;90:F201-F207. doi: 10.1136/adc.2004.062745

For many years, newborn infants admitted to neonatal intensive care units have had routine electrocardiography and been monitored for respiratory rate, heart rate, oxygen saturation, and blood pressure. Only recently has it also been considered important to monitor brain function using continuous electroencephalography. The role of cerebral function monitoring in sick full term and preterm infants is reviewed.

See end of article for authors' affiliations

......................

Correspondence to: Dr de Vries, Department of Neonatology, KE 04.123. 1, Wilhelmina Children's Hospital, PO Box 85090, 3508 AB Utrecht, the Netherlands; I.devries@ wkz.azu.nl

Accepted

8 December 2004
W hereas monitoring of respiratory rate, heart rate, oxygen saturation, and blood pressure has been well integrated into the routine care of any newborn infant admitted to a neonatal intensive care unit for many years, only recently was it considered important, or possible, to use continuous electroencephalography (EEG) to monitor brain function.

Maynard $^{1}$ originally designed the cerebral function monitor (CFM) in the late 1960s. The main clinical application, investigated by Prior, ${ }^{2}$ was monitoring adult patients during anaesthesia and in intensive care after cardiac arrest, during status epilepticus, and after heart surgery. A description of the device and initial experiences with it have been compiled into a well known book. ${ }^{3}$ The term amplitude integrated EEG (aEEG) is currently preferred to denote a method for electrocortical monitoring, whereas CFM is used to refer to specific equipment. The recorded from one pair of biparietally placed electrodes (corresponding to $\mathrm{P}_{3}$ and $\mathrm{P}_{4}$ according to the international EEG 10-20 classification, ground $\mathrm{F}_{\mathrm{z}}$ ). Both thin subdermal needle electrodes and disc and hydrogel electrodes have been used. Although application of needle electrodes is considered more invasive, it involves less handling, and the impedance usually remains below $5 \mathrm{k}^{\prime} \Omega$ for several days. The use of a single channel does not allow information about hemispheric asymmetry to be obtained. The use of two channels (bilateral frontoparietal electrodes) may be of clinical significance, especially in children with a unilateral brain lesion. The signal is amplified and passed through an asymmetrical band pass filter, which strongly attenuates activity below $2 \mathrm{~Hz}$ and above $15 \mathrm{~Hz}$ in order to minimise artefacts from such sources as sweating, muscle activity, and electrical interference. Additional processing includes semilogarithmic amplitude compression, rectification, and time compression. The signal is recorded on paper with a semilogarithmic scale at slow speed $(6 \mathrm{~cm} / \mathrm{h})$ at the cot side (fig $\mathrm{l})$. A second trace continuously records the electrode impedance. EEG signal for the single channel aEEG is usually
The band width in the output reflects variations in minimum and maximum EEG amplitude, both of which depend on the maturity and severity of illness of the newborn infant. The use of a semilogarithmic scale to plot the output means that changes in background activity of very low amplitude $(<5 \mu \mathrm{V})$ are enhanced. The cerebral function analysing monitor (CFAM; RDM Consultants Ltd, Uckfield, East Sussex, UK) is a further development of the CFM. aEEG monitoring can be carried out from two to four channels, and a frequency analysis can be performed and presented as percentage activity within each of the classic frequency bands. ${ }^{4}$ More recently, several digital EEG monitoring systems have been developed which allow the raw EEG to be displayed and stored continuously with online trend analysis of the aEEG, using one, two, or more channels.

The first studies performed in newborn infants are from the early 1980s. ${ }^{5-7}$ In most of the studies, aEEG was recorded with the CFM (CFM 4640 or 5330; Lectromed Devices Ltd, Letchworth, Hertfordshire, UK). In the initial studies, maturation of the background pattern was assessed in low risk preterm infants. ${ }^{6-8}$ However, it quickly became clear that long term recordings in high risk, full term infants with neonatal encephalopathy was especially interesting. ${ }^{5}$ 9

\section{RATIONALE FOR THE USE OF aEEG IN THE NEONATAL BRAIN}

Interest in the neonatal brain has increased considerably during the last decade or so. This is in part due to better diagnostic methods in the acute and subacute stage. Magnetic resonance imaging provides important information about the presence and extent of structural lesions. Information on cerebral metabolism can be obtained during the same examination using magnetic resonance spectroscopy. ${ }^{10}$ Although magnetic resonance imaging is now often performed within a few days of birth, information is preferably obtained within hours of delivery for selection of infants for early intervention studies, such as hypothermia. ${ }^{11}$ aEEG provides information about the functional integrity of the brain and can be used immediately after admission or even in the referring hospital.

\footnotetext{
Abbreviations: aEEG, amplitude integrated electroencephalography; CFM, cerebral function monitor; EEG, electroencephalography; HIE, hypoxic-ischaemic
} encephalopathy 


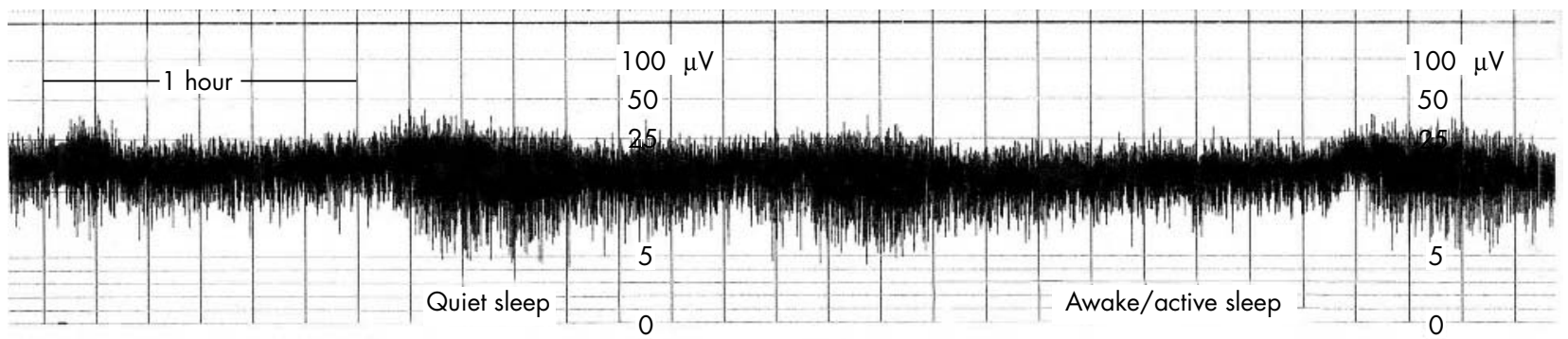

Figure 1 Continuous normal voltage background pattern with sleep-wake cycling recorded on a CFM 5330 (Lectromed).

\section{NEONATAL ENCEPHALOPATHY AND NEONATAL SEIZURES}

Despite advances in obstetric and neonatal care, perinatal hypoxic-ischaemic encephalopathy (HIE) is still experienced by three to four infants per 1000 live term births, and is associated with death or an adverse neurodevelopmental outcome in a considerable number of these. aEEG monitoring of newborn infants with HIE has been used for assessment of aEEG background activity, early evaluation of brain function, detection of seizures, evaluation of the effect of anticonvulsive drugs, selection of patients for neuroprotective intervention, and prediction of neurodevelopmental outcome as early as the first hours after birth.

\section{ASSESSMENT OF aEEG BACKGROUND PATTERN}

Assessment of the aEEG recording should start with the background pattern. Then the presence or absence of seizure activity should be noted.

Different methods have been used to classify the variations in background pattern. Some describe the different patterns, ${ }^{12-14}$ whereas others have made a distinction based on the voltage as level of the upper and lower margins of the activity. ${ }^{15}$ The classification of background patterns distinguishes five different patterns in full term infants (fig 2):

(a) the continuous normal voltage pattern is a continuous trace with a voltage of $10-25(-50) \mu \mathrm{V}$ (fig $2 \mathrm{~A}$ ); (b) discontinuous normal voltage pattern is a discontinuous trace, where the low voltage is predominantly above $5 \mu \mathrm{V}$ (no burst suppression) (fig $2 \mathrm{~B}$ );

(c) discontinuous background pattern (burst suppression); periods of low voltage (inactivity) intermixed with bursts of higher amplitude (fig 2C);

(d) continuous background pattern of very low voltage (around or below $5 \mu \mathrm{V}$ ) (fig 2D)

(e) very low voltage, mainly inactive trace with activity below $5 \mu \mathrm{V}$ (flat trace) (fig $2 \mathrm{E}$ )

There have been several studies in which aEEG and standard EEG were performed simultaneously to compare the two techniques. Overall there appeared to be a good correlation between the aEEG and EEG background pattern in the sick full term infant. ${ }^{16}{ }^{17}$ In the presence of a discontinuous normal voltage background pattern, a mild discrepancy was sometimes noted, showing excessive discontinuity on the standard EEG. ${ }^{17}$ Infants with this background pattern usually normalise within the first 24 hours, but some deteriorate and develop a burst suppression pattern. A standard EEG is therefore especially important in this intermediate group to obtain more detailed information, especially about possible intermixed electrical discharges (see below).

In the classification of al Naqeeb et $a,^{15}$ amplitude was classified as normal when the upper margin of the band of
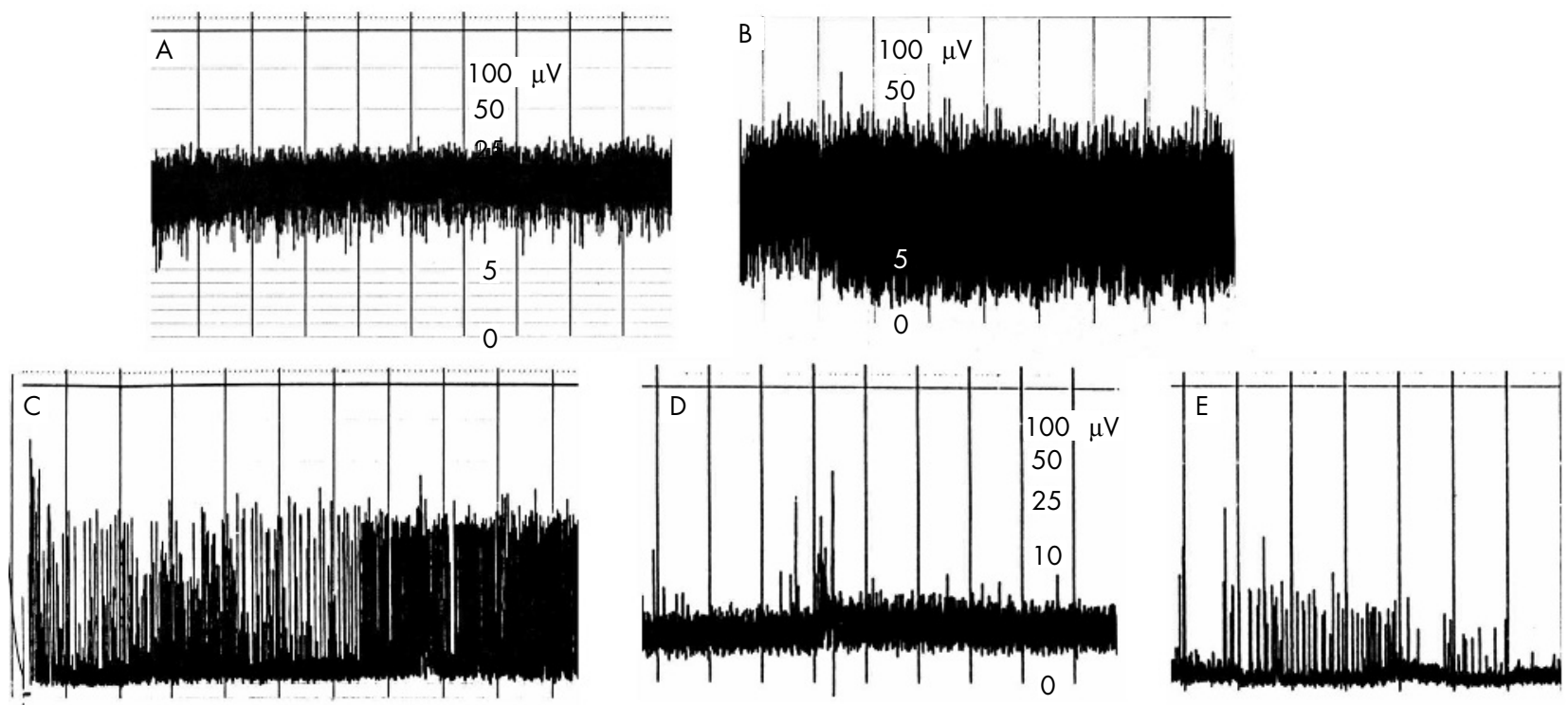

Figure 2 Different background patterns recorded on a CFM 5330 (Lectromed). (A) Continuous normal voltage; (B) discontinuous normal voltage; (C) burst suppression; (D) continuous low voltage; (E) flat trace. 

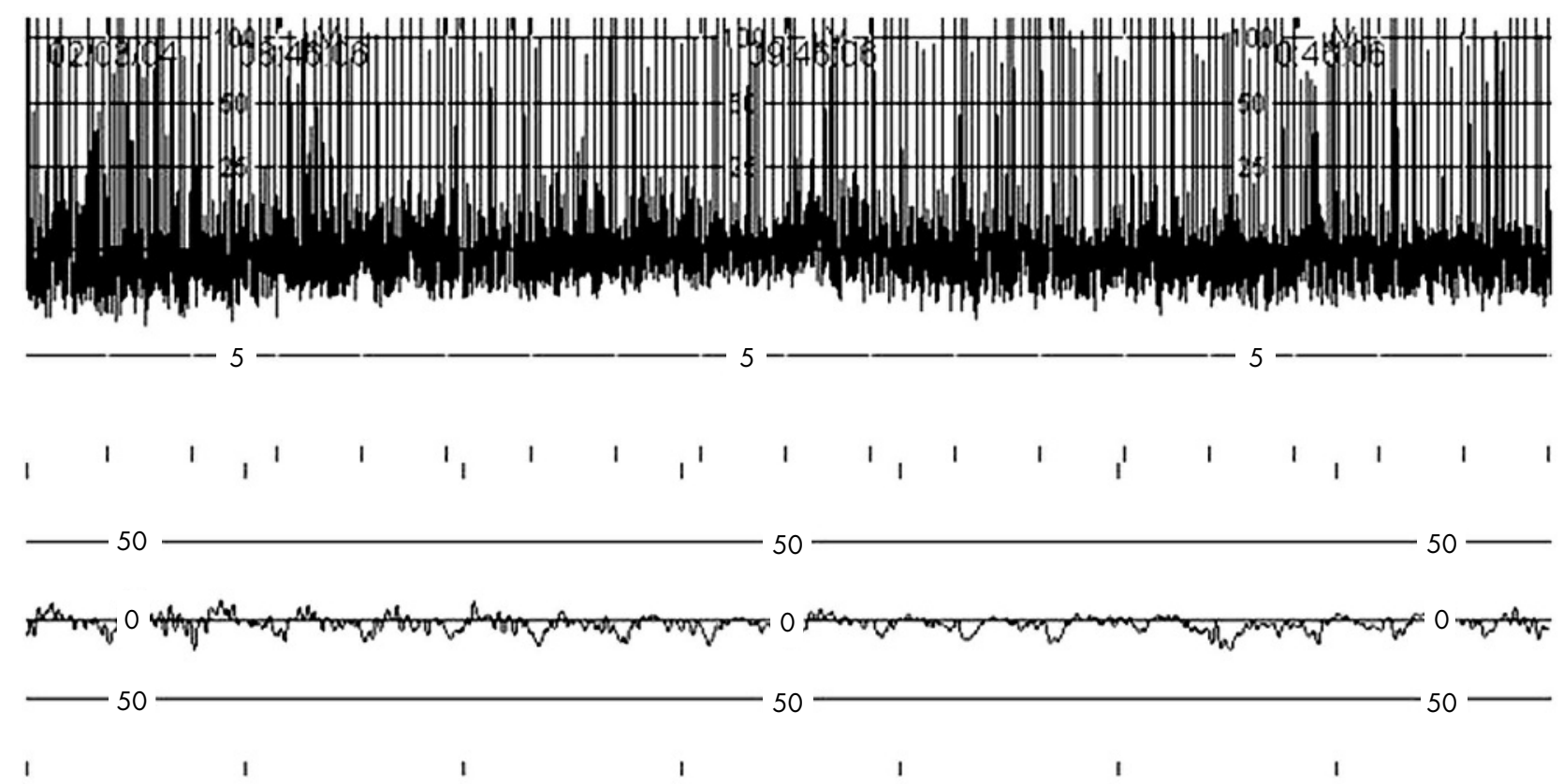

Figure 3 Full term infants with severe hypoxic-ischaemic encephalopathy. The infants started off with an isoelectric trace and subsequently developed electrical discharges on a severe burst suppression pattern. After some hours, a drift of the baseline is noted with a minimum voltage above $5 \mu \mathrm{V}$ even though a burst suppression pattern can still be recognised. The raw electroencephalogram appears to show a pulse waveform (Olympic 6000).

aEEG activity was $>10 \mu \mathrm{V}$ and the lower margin $>5 \mu \mathrm{V}$ (fig 2A), moderately abnormal when the upper margin of the aEEG band was $>10 \mu \mathrm{V}$ and the lower margin $\leqslant 5 \mu \mathrm{V}$ (fig $2 \mathrm{~B}$ and latter half of $2 \mathrm{C}$ ), and suppressed when the upper margin of the aEEG band was $<10 \mu \mathrm{V}$ (fig $2 \mathrm{D}, \mathrm{E}$ ). When the latter classification system is used, care should be taken with the so-called drift of the baseline, which can significantly raise the baseline, while still showing a burst suppression pattern. This drift of the baseline is especially seen in infants with a severely depressed background pattern and is probably due to interference from extracranial activity-for example, electrocardiography (fig 3 ). Both the pattern and the voltage should be considered to avoid incorrect classification of a background pattern into a "better" category. In addition, the underlying EEG signal should be examined to assist in the recognition of interference, which may cause the drift.

Over the years quite a number of groups have studied the relation between the background pattern recorded within 3-12 hours of birth and subsequent neurodevelopmental outcome. ${ }^{12} 131819$ The first studies assessed the aEEG during the first 12-24 hours, but with recent interest in early intervention, it has now been assessed as early as three to six hours after birth, to see whether it could play a role in

Table 1 Predictive value of a poor background pattern (burst suppression, continuous low voltage, flat trace) for poor neurodevelopmental outcome in the neonatal period and infancy

\begin{tabular}{lllll}
\hline $\begin{array}{l}\text { Time after } \\
\text { birth (h) }\end{array}$ & Sensitivity & Specificity & PPV & NPV \\
\hline $6^{12}$ & 95 & 89 & 86 & 96 \\
$6^{18}$ & 94 & 79 & 84 & 92 \\
$6^{13}$ & 91 & 86 & 86 & 96 \\
$3^{13}$ & 85 & 77 & 78 & 84 \\
\hline
\end{tabular}

Values are percentages.

PPV, Positive predictive value; NPV, negative predictive value. selection of infants at risk of developing neonatal encephalopathy. The predictive value of the presence of a poor background pattern (burst suppression, continuous low voltage, flat trace) for subsequent poor neurodevelopmental outcome was assessed in these different studies. The predictive values obtained by different groups were very similar (table 1). Both positive and negative predictive values were slightly lower when aEEG was assessed at three rather than six hours after birth, but they were still considered sufficiently high to use this technique for early selection in hypothermia intervention studies. A more recently published study indicates that the sensitivity and specificity can be increased further when early aEEG evaluation is coupled with a clinical evaluation. ${ }^{20}$

\section{DETECTION OF EPILEPTIC SEIZURE ACTIVITY}

Epileptic seizures are common in full term infants admitted with HIE. Several studies have shown that, although the initial seizures are often clinical, subsequent seizures after administration of the first anti-epileptic drug are often subclinical. ${ }^{21}{ }^{22}$ This is referred to as electroclinical dissociation or "uncoupling". Bye and Flanagan ${ }^{23}$ showed evidence of reduced clinical features after sequential administration of anti-epileptic drugs. Using prolonged video/EEG monitoring, they found that $85 \%$ of all seizures were not associated with clinical manifestations. This phenomenon was recently also addressed by Sher et al. ${ }^{21}$ They found that $58 \%$ of the infants with seizures persisting after treatment with phenobarbitone or phenytoin showed uncoupling of electrical and clinical seizures. $^{321}$ Boylan et $a l^{22}$ also found that electrographic seizures were common in infants with severe HIE after initial treatment with phenobarbitone. The aEEG can play an important role in the detection of these subclinical seizures. The effect of anti-epileptic drugs can only be assessed when continuous aEEG or standard EEG registration is used (fig 4).

Seizures are most often recognisable on the aEEG as a rapid rise in both the lower and upper margins of the trace. Arousal during care procedures often results in a transient rise in the aEEG background and may be misinterpreted as 

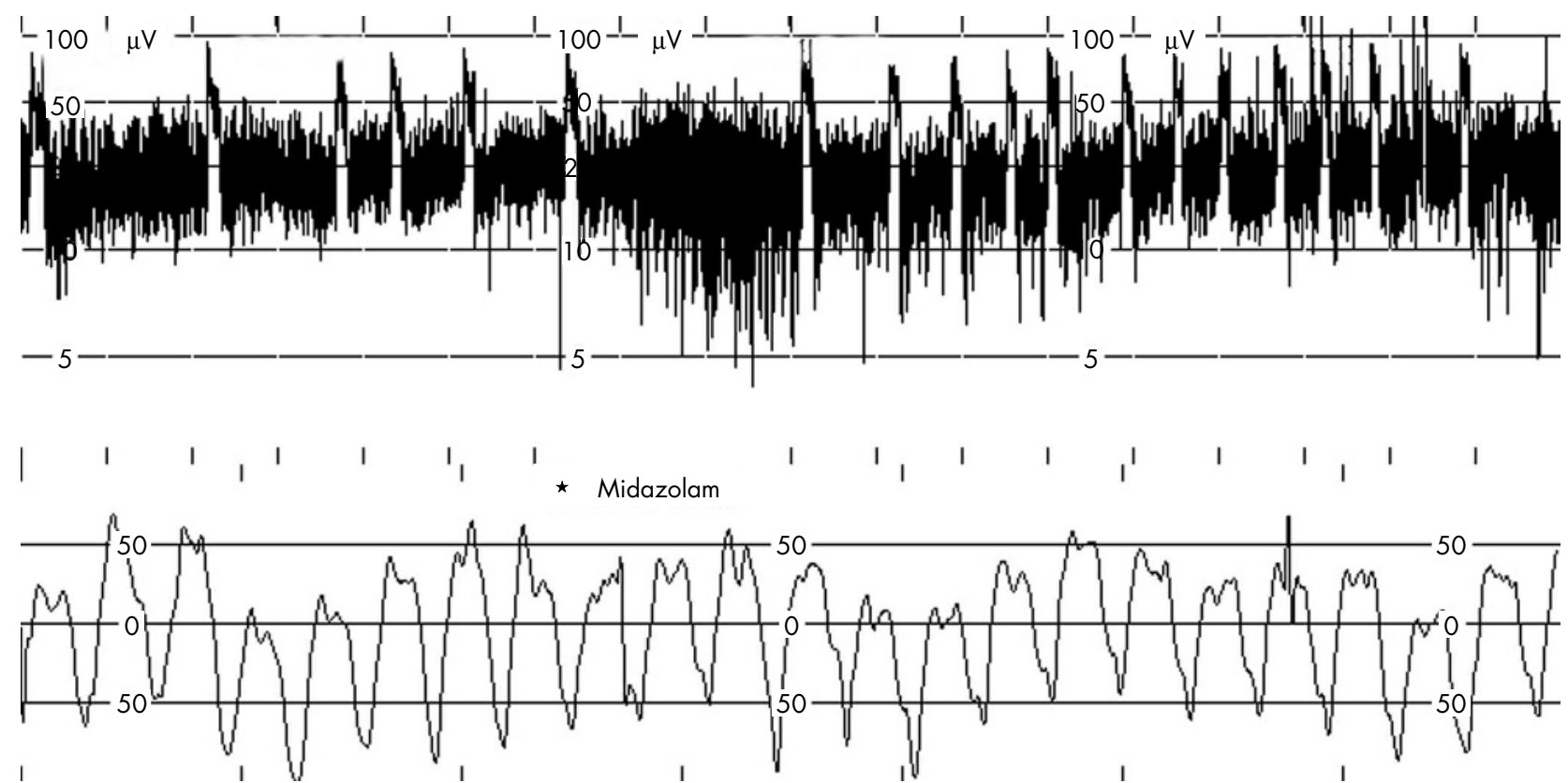

Figure 4 Repetitive epileptic discharges on a continuous normal voltage background pattern. Raw electroencephalogram, shown at the asterisk, shows rhythmic activity. Midazolam is also given at this time. Repetitive discharges continued without any clinical signs (Olympic 6000).

epileptic seizure activity. It is therefore very important that all care procedures are documented on the traces to facilitate correct interpretation. A status epilepticus usually looks like a "saw tooth" pattern, but a continuously raised background pattern can also sometimes be seen. Correct interpretation is only possible when a simultaneous raw EEG is available (fig 5).

It has been questioned whether a single channel aEEG is sufficiently reliable to detect seizure discharges. Owing to the nature of the single channel recording, it is not surprising that very brief seizure activity, as well as focal seizure activity, may be missed. ${ }^{17}{ }^{24}$ The data in the study by Toet $e t a l^{17}$ did not identify focal seizures in two of 10 children who were noted to have electrical discharges during the simultaneous aEEGEEG recording. The data in the study by Rennie $e t a^{24}$ were less promising. They asked four neonatologists with rather limited experience (three to five hours) to analyse aEEG traces recorded at three different speeds. The infants were a mixture of preterm and full term infants. The seizures were poorly detected at the most commonly used speed $(6 \mathrm{~cm} / \mathrm{h})$ with a sensitivity of only $38 \%$. As the authors suggested themselves, these disappointing results may be attributed to

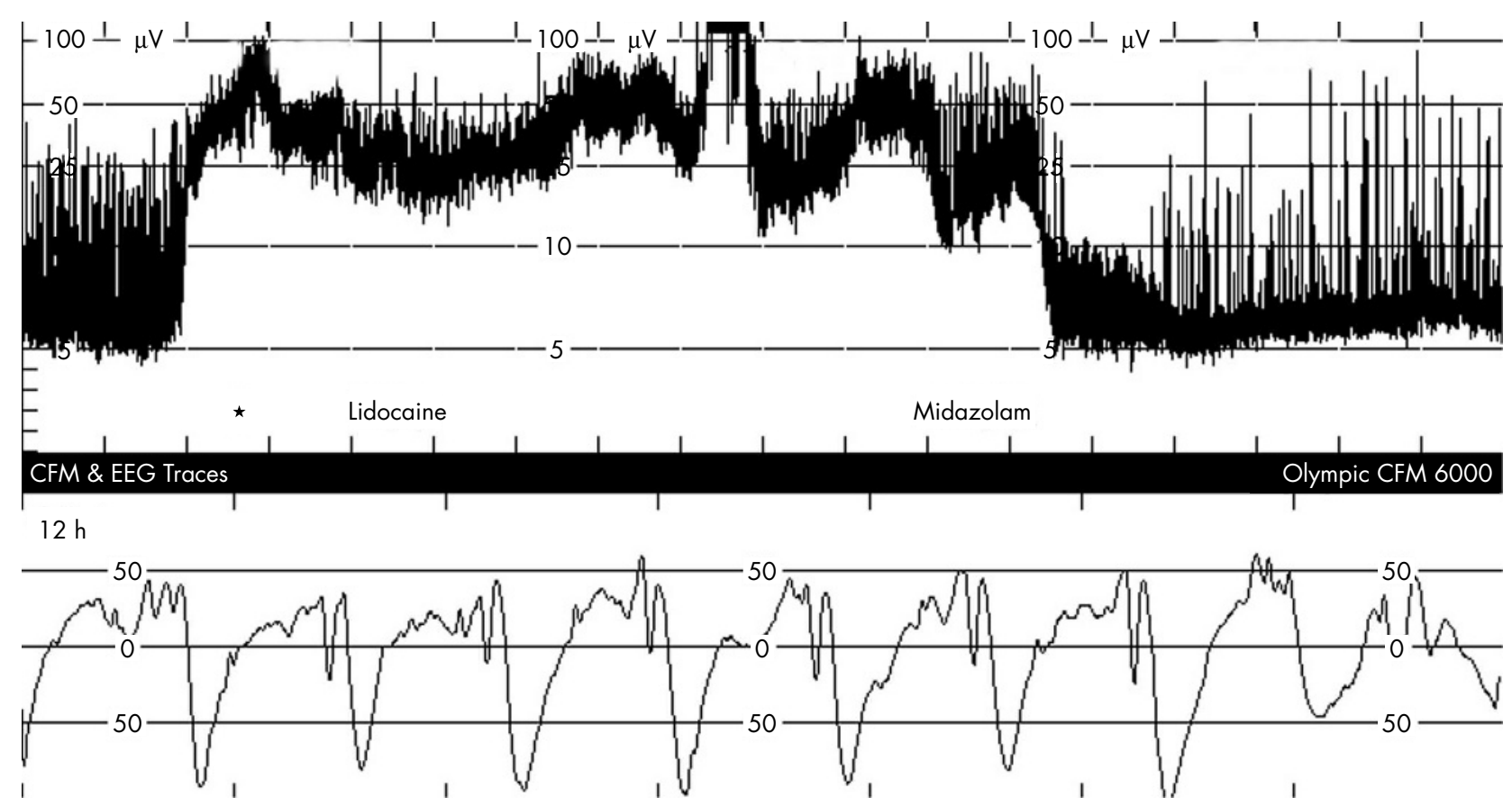

Figure 5 Status epilepticus with a continuously raised voltage over a period exceeding one and a half hours. Raw electroencephalogram taken at the asterisk. Interruption is achieved after midazolam administration (Olympic 6000). 


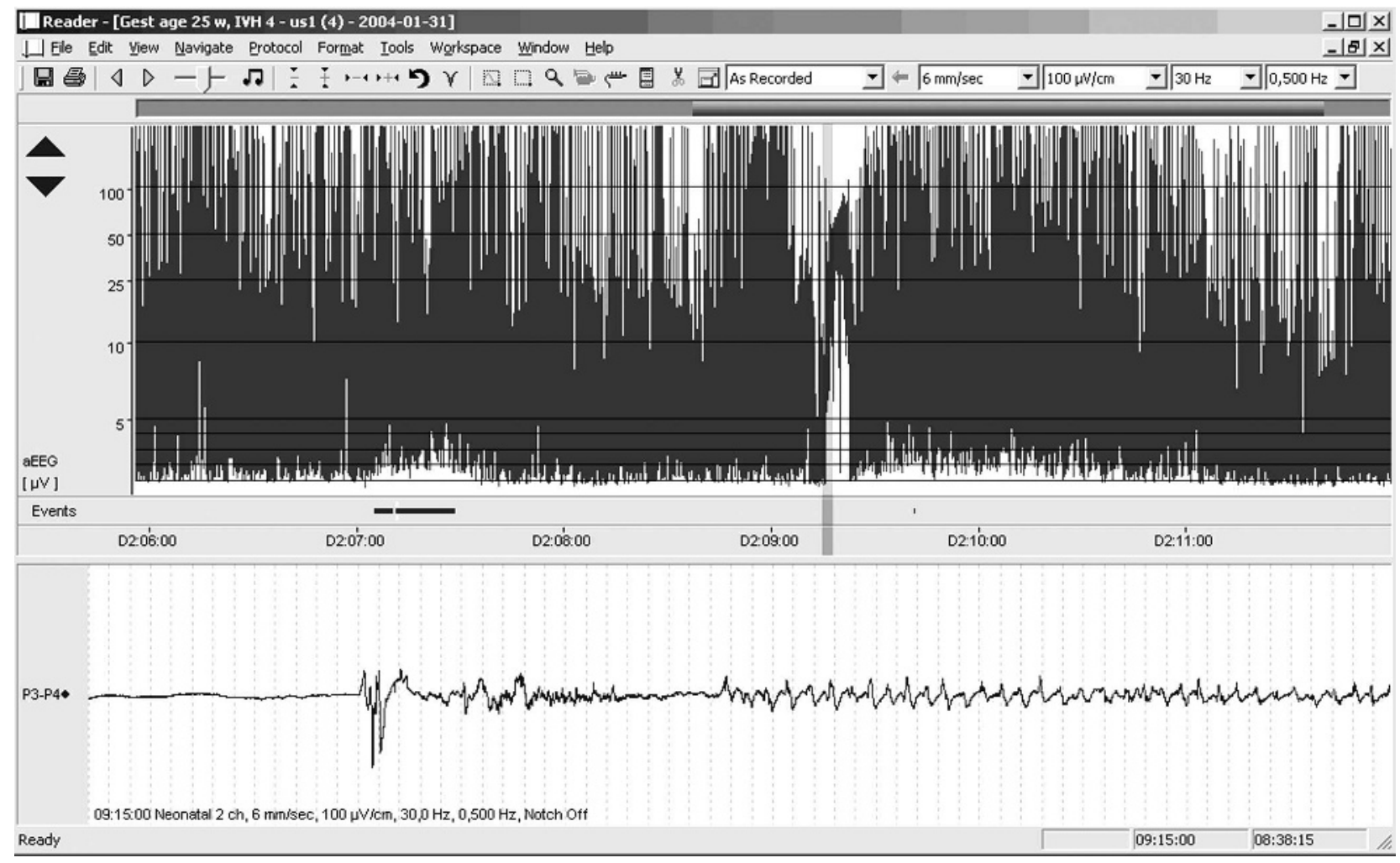

Figure 6 Preterm infant, born at 25 weeks gestation with intraventricular haemorrhage grade 4 on ultrasound. The infant is mechanically ventilated and sedated with a continuous infusion of morphine. The amplitude integrated electroencephalographic (aEEG) recording has a duration of six hours and shows discontinuous background activity (burst suppression) without cyclical changes. A short seizure develops after 3.5 hours of recording, and can be seen in the aEEG as an abrupt and transient rise in the lower level of the trace. Below is 60 seconds of the raw EEG at the start of the seizure, corresponding to the shaded vertical line in the aEEG (NicoletOne; Vyasis).

the limited experience of the examiners. Furthermore, the group was inhomogeneous, with eight of the 19 infants having a gestational age $<33$ weeks, and five of the infants only showing focal seizures. This study stresses the fact that experience is required to be able to interpret aEEG traces. Ample examples can be studied in an aEEG atlas ${ }^{25}$ and also at a website (http://www.azzopardi.freeserve.co.uk/CFM/ olympic_cfm_manual.pdf). The study of Rennie et al ${ }^{24}$ also shows that one should be aware of the limitations of the technique. Focal seizures do, however, often generalise at a later stage and will then be identified by the aEEG. Some newer machines offer two channels, which may allow better detection of focal seizures, for instance in children with neonatal stroke. Newer systems also provide access to the raw EEG, which can often help to identify brief periods of seizure activity, which are not easily detected on the older aEEG equipment. Even though it is possible that some focal or very brief seizures will not be detected, the long duration of the aEEG registration outweighs the limitations of obtaining detailed information during a much shorter, 30 minute, standard EEG recording.

\section{ASSESSMENT OF SLEEP-WAKE CYCLING}

The narrow trace in the aEEG represents more continuous activity during wakefulness or active sleep, and the periods of widening of the trace represent more discontinuous activity during quiet sleep (fig 1). It was recently shown that the presence, time of onset, and quality of sleep-wake cycling reflects the severity of the hypoxic-ischaemic insult to which newborns have been exposed. ${ }^{26}$ The time of onset of sleepwake cycling was shown to predict neurodevelopmental outcome based on whether it returns before 36 hours (good outcome) or after 36 hours (bad outcome). With this method, an accurate prediction was made in $82 \%$ of the 171 newborn infants with different degrees of HIE.

These data are in agreement with two other recent reports. Ter Horst et $_{\text {al }}{ }^{27}$ studied 30 full term newborns with HIE. They found sleep-wake cycling in 10/13 newborns with a normal outcome, in 3/6 with a mildly abnormal outcome, and in none of 11 who had an abnormal outcome or died. Early sleep-wake cycling was also noted to correlate with a good outcome in a study by Thorngren-Jerneck et al, ${ }^{28}$ who compared aEEG and positron emission tomography findings in 19 term newborns with HIE.

\section{THE PRETERM INFANT}

aEEG is also feasible for monitoring cerebral activity in preterm infants during intensive care. In parallel with the EEG, aEEG background activity is more discontinuous in preterm infants. Normative values for aEEG background activity at different gestational ages have been published. ${ }^{29} 30$ Sleep-wake cycling can be clearly identified in the aEEG from around 30 weeks gestation, but also at 25-26 weeks gestational age a cyclical pattern resembling sleep-wake cycling can be seen in stable infants. Effects from some common drugs-for example, surfactant, morphine, and diazepamcan be readily seen in the aEEG of preterm infants. ${ }^{31}{ }^{32}$

\section{PREDICTION OF OUTCOME}

Early prediction of outcome from aEEG is a more complicated issue in preterm infants than in full term infants. In the most immature infants, factors other than initial brain function 
may influence long term neurodevelopmental outcome-for example, bronchopulmonary dysplasia and late onset sepsis-which makes prediction of outcome from early EEG less certain. ${ }^{33}$ Nevertheless, several EEG and aEEG studies have shown early background depression to correlate with the severity of a periventricular-intraventricular haemorrhage. ${ }^{34-38}$ A mainly discontinuous background pattern can be considered as normal in most infants below 30 weeks gestation. Consequently, a classification based on the type of background pattern is not feasible for preterm infants. By measuring, for example, percentage of activity above a predefined level, for example $3 \mu \mathrm{V}$, or by counting burst activity, a quantitative measure of the degree of continuity or discontinuity can be obtained. In preterm infants with small periventricular-intraventricular haemorrhages, aEEG background is initially depressed but recovers within the first days of life, whereas the aEEG background remains depressed for longer periods in infants with larger haemorrhages. By counting the number of bursts/hour, early prediction of gross neurological outcome could already be made during the first 24-48 hours of life in preterm infants with large haemorrhages. ${ }^{39}$

\section{DETECTION OF EPILEPTIC SEIZURE ACTIVITY}

Epileptic seizure activity in preterm infants can be identified in the same way as in full term infants. Epileptic seizure activity, often without clinical symptoms, is very common in the aEEG during development of intracerebral haemorrhages. ${ }^{37}$ Although not studied, it is our impression that epileptic seizure activity in preterm infants may be more difficult to assess, as it may be fragmentary, and status epilepticus with the typical saw tooth pattern is rarely seen. The new aEEG monitors, including display of the raw EEG, will contribute to more accurate diagnosis of seizure activity in preterm infants (fig 6).

\section{ASSESSMENT OF SLEEP-WAKE CYCLING}

A cyclical pattern including periods with more continuous activity can be seen in aEEG of stable preterm infants. From around 32 weeks gestation, it is clear that this represents sleep-wake cycling. ${ }^{40}$ Periods with discontinuous activity represent quiet sleep. Wakefulness and active sleep are represented by periods with continuous activity and cannot be distinguished in the aEEG without simultaneous observation of the infant. A recent study on aEEG scoring in infants from 24 to 39 weeks gestation showed that development of a cyclical pattern in preterm infants is closely related to increasing postconceptional age. ${ }^{14}$ The aEEG has been used for quantifying quiet sleep in preterm infants when evaluating care procedures such as incubator covers and developmental care. ${ }^{41}{ }^{42}$ Early presence of sleep-wake cycling in the aEEG was also associated with better outcome in infants with large haemorrhages. ${ }^{39}$

\section{aEEG: PAST, PRESENT, AND FUTURE DIRECTIONS}

Experience with continuous aEEG is increasing, and many neonatal intensive care units would now find it hard to treat a full term infant with HIE without having access to this equipment. The use of this continuous monitoring device has also raised a number of questions. With longer recordings, it has become easier to see that neonatal seizures are difficult to control with commonly used anti-epileptic drugs. ${ }^{43}$ Other drugs such as lidocaine and midazolam have been introduced and need to be assessed further. ${ }^{4-47}$ The anti-epileptic effect of these drugs can only be seen with the use of continuous aEEG monitoring. Using a continuous monitor, we have become aware that subclinical seizures are very common. There are now some data to support the view that repeated seizures may have an adverse effect on the developing human brain and even that the severity of seizures in newborns with perinatal asphyxia is independently associated with brain injury. ${ }^{45449}$ Although the presence of brief rhythmical discharges was shown to be associated with an adverse outcome, ${ }^{49}$ there is as yet no real evidence that subclinical seizures are harmful to the neonatal brain. Concerns have also been expressed about the apoptotic neurodegenerative effect of anti-epileptic drugs in the developing rat brain at plasma concentrations relevant for seizure control in humans. $^{50}$ The first randomised study of treatment of subclinical seizures (SuSeQue) has just started, with 10 neonatal units participating in the Netherlands and Belgium.

aEEG is also useful in the high risk preterm infant even though this has not yet been evaluated as extensively as in the full term infant. It is most likely that aEEG will soon be part of the routine care in the neonatal unit and some of the larger district general hospitals, and one would hope and expect that some of the questions raised by using this device will be answered in the not too distant future.

\section{ACKNOWLEDGEMENTS}

We are especially grateful to Ingmar Rosén, Ann-Cathrine Berg, Kees van Huffelen, and Mona Toet for good collaboration and continuous support in the work with aEEG. We also thank Ted Weiler (Olympic Medical Systems) for valuable comments on the manuscript and Lars Johan Ahnlide (Cephalon) for technical support.

\section{Authors' affiliations}

L S de Vries, Department of Neonatology, Wilhelmina Children's Hospital, UMC, Utrecht, the Netherlands

L Hellström-Westas, Department of Pediatrics, University Hospital, Lund, Sweden

Competing interests: none declared

\section{REFERENCES}

1 Maynard DE. EEG analysis using an analogue frequency analyser and a digital computer. Electroencephalogr Clin Neurophysiol 1967;23:487.

2 Prior PF. EEG monitoring and evoked potentials in brain ischaemia. Br J Anaesth 1985;57:63-81.

3 Prior PF, Maynard DE. Monitoring cerebral function. Long-term recordings of cerebral electrical activity and evoked potentials. Amsterdam: Elsevier, 1986:1-441.

4 Murdoch-Eaton D, Darowski M, Livingston J. Cerebral function monitoring in paediatric intensive care: useful features for predicting outcome. Dev Med Child Neurol 12001:91-6.

5 Bierre I, Hellström-Westas L, Rosen I, et al. Monitoring of cerebral function after severe birth asphyxia in infancy. Arch Dis Child 1983;58:997-1002.

6 Verma UL, Archbald F, Tejani NA, et al. Cerebral function monitor in the neonate. I. Normal patterns. Dev Med Child Neurol 1984;26:154-61.

7 Viniker DA, Maynard DE, Scott DF. Cerebral function studies in neonates. Clin Electroencephalogr 1984; 15:185-92.

8 Thornberg $\mathbf{E}$, Thiringer K. Normal pattern of the cerebral function monitor trace in term and preterm neonates. Acta Paediatr Scand 1990;79:20-5.

9 Hellstrőm-Westas L, Rosen I, Svenningsen NW. Silent seizures in sick infants in early life. Acta Paediatr Scand 1985;74:741-8.

10 Robertson NJ, Wyatt JS. The magnetic resonance revolution in brain imaging: impact on neonatal intensive care. Arch Dis Child Fetal Neonatal Ed 2004;89:F193-7.

11 Gluckman PD, Wyatt JS, Azzopardi D, et al. Selective head cooling with mild systemic hypothermia after neonatal encephalopathy: multicentre radomised trial. Lancet 2005;365:665-70.

12 Hellström-Westas L, Rosen I, Svenningsen NW. Predictive value of early continuous amplitude integrated EEG recordings on outcome after severe birth asphyxia in full term infants. Arch Dis Child Fetal Neonatal Ed 1995;72:F34-8.

13 Toet MC, Hellstrőm-Westas L, Groenendaal F, et al. Amplitude integrated EEG 3 and 6 hours after birth in full term neonates with hypoxic-ischaemic encephalopathy. Arch Dis Child Fetal Neonatal Ed 1999;81:F19-23.

14 Burdjalov VF, Baumgart S, Spitzer AR. Cerebral function monitoring: a new scoring system for the evaluation of brain maturation in neonates. Pediatrics 2003; 112:855-61.

15 Al Naqeeb N, Edwards AD, Cowan F, et al. Assessment of neonatal encephalopathy by amplitude integrated electroencephalography. Pediatrics 1999;103:1263-71.

16 Hellstrőm-Westas L. Comparison between tape-recorded and amplitude integrated EEG monitoring sick newborn infants. Acta Paediatr Scand 1992;81:812-19. 
17 Toet MC, van der Meij W, de Vries LS, et al. Comparison between simultaneously recorded amplitude integrated EEG (Cerebral Function Monitor) and standard EEG in neonates. Pediatrics 2002;109:772-9.

18 Eken P, Toet MC, Groenendaal F, et al. Predictive value of early neuroimaging, pulsed Doppler and neurophysiology in full term infants with hypoxic-ischemic encephalopathy. Arch Dis Child Fetal Neonatal Ed 1995;73:F75-80.

19 Thornberg E, Ekstrom-Jodal B. Cerebral function monitoring: a method of predicting outcome in term neonates after severe perinatal asphyxia. Acta Paediatr 1994;83:596-601.

20 Shalak LF, Laptook AR, Velaphi SC, et al. Amplitude-integrated electroencephalography coupled with an early neurologic examination enhances prediction of term infants at risk for persistent encephalopathy. Pediatrics 2003;111:351-7.

21 Sher MS, Alvin J, Gaus L, et al. Uncoupling of EEG-clinical neonatal seizures after antiepileptic drug use. Pediatr Neurol 2003;28:277-80.

22 Boylan GB, Rennie JM, Pressler RM, et al. Phenobarbitone, neonatal seizures, and video-EEG. Arch Dis Child Fetal Neonatal Ed 2002;86:F165-70.

23 Bye A. M, Flanagan D. Spatial and temporal characteristics of neonatal seizures. Epilepsia 1995;36:1009-16.

24 Rennie JM, Chorley G, Boylan GB, et al. Non-expert use of the cerebral function monitor for neonatal seizure detection. Arch Dis Child Fetal Neonatal Ed 2004;89:F37-40.

25 Hellström-Westas L, de Vries LS, Rosen I. An atlas of amplitude-integrated EEGs in the newborn. London: Parthenon Publishing, 2003.

26 Osredkar D, Toet MC, van Rooij LGM, et al. Sleep-wake cycling on amplitudeintegrated EEG in full-term newborns with hypoxic-ischemic encephalopathy. Pediatrics 2005;115:327-32.

27 Ter Horst HJ, Sommer C, Bergman KA, et al. Prognostic significance of amplitude-integrated EEG during the first 72 hours after birth in severely asphyxiated neonates. Pediatr Res 2004;55:1026-33.

28 Thorngren-Jerneck K, Hellstrom-Westas L, Ryding E, et al. Cerebral glucose metabolism and early EEG/aEEG in term newborn infants with hypoxicischemic encephalopathy. Pediatr Res 2003;54:854-60.

29 Thornberg E, Thiringer K. Normal patterns of cerebral function monitor traces in term and preterm neonates. Acta Paediatr Scand 1990;79:20-5.

30 Olischar M, Klebermass K, Kuhle S, et al. Reference values for amplitudeintegrated electroencephalographic activity in preterm infants younger than 30 weeks' gestational age. Pediatrics 2004;113:e61-6.

31 Hellström-Westas L, Bell AH, et al. Cerebroelectrical depression following surfactant treatment in preterm neonates. Pediatrics 1992;89:643-7.

32 Bell AH, Greisen G, Pryds O. Comparison of the effects of phenobarbitone and morphine administration on EEG activity in preterm babies. Acta Paediatr 1993:82:35-9

33 Tharp BR, Scher MS, Clancy RR. Serial EEGs in normal and abnormal infants with birthweights less than 1200 grams: a prospective study with long term follow-up. Neuropediatrics 1989;20:64-72.
34 Watanabe K, Hakamada S, Kuroyanagi M, Yamazaki T, Takeuchi T. Electroencephalographical study of intraventricular hemorrhage in the preterm infant. Neuropediatrics 1983;14:225-30.

35 Clancy RR, Tharp BR, Enzman D. EEG in premature infants with intraventricular hemorrhage. Neurology 1984;34:583-90.

36 Connell J, deVries L, Oozeer R, et al. Predictive value of early continuous electroencephalogram monitoring in ventilated preterm infants with intraventricular hemorrhage. Pediatrics 1988;82:337-43.

37 Greisen G, Hellström-Westas L, Lou H, et al. EEG depression and germinal layer haemorrhage in the newborn. Acta Paediatr Scand 1987;76:519-25.

38 Hellström-Westas L, Rosen I, Svenningsen NW. Cerebral function monitoring during the first week of life in extremely small low birthweight (ESLBW) infants. Neuropediatrics 1991;22:27-32.

39 Hellström-Westas L, Klette H, Thorngren-Jerneck K, et al. Early prediction of outcome with aEEG in premature infants with large intraventricular haemorrhages. Neuropediatrics 2001;32:319-24.

40 Greisen G, Hellström-Westas $L$, Lou $H$, et al. Sleep-waking shifts and cerebral blood flow in stable preterm infants. Pediatr Res 1985;19:1156-9.

41 Hellström-Westas L, Inghammar M, Isaksson K, et al. Short term effects of incubator covers on quiet sleep in stable preterm infants. Acta Paediatr 2001;90:1004-8

42 Westrup B, Hellström-Westas L, Stjernqvist K, et al. No indications of increased quiet sleep in infants who received care based on the Newborn Individualized Developmental Care and Assessment Program (NIDCAP). Acta Paediatr 2002;91:318-22.

43 Painter MJ, Scher MS, Stein AD, et al. Phenobarbital compared with phenytoin for the treatment of neonatal seizures. N Engl J Med 1999:341:485-9.

44 Hellström-Westas $L$, Svenningsen NW, Westgren U, et al. Lidocaine for treatment of severe seizures in newborn infants. II. Blood concentrations of lidocaine and metabolites during intravenous infusion. Acta Paediatr 1992:81:35-9.

45 Boylan GB, Rennie JM, Chorley G, et al. Second-line anticonvulsant treatment of neonatal seizures. Neurology 2004;62:486-8

46 Van Rooij LCM, Toet MC, Rademaker MCA, et al. Cardiac arrhythmia in neonates receiving lidocaine as anticonvulsive treatment. Eur J Pediatr 2004; 163:637-41.

47 van Leuven K, Groenendaal F, Toet MC, Schobben AFAM, et al. Midazolam and amplitude integrated EEG in asphyxiated full-term neonates. Acta Paediatr 2004;93:1221-7.

48 Miller SP, Weiss J, Barnwell A, et al. Seizure-associated brain injury in term newborns with perinatal asphyxia. Neurology 2002;58:542-8.

49 Oliveira AJ, Nunes M, Haertel LM, et al. Duration of rhythmic EEG patterns in neonates: new evidence for clinical and prognostic significance of brief rhythmic discharges. Clin Neurophysiol 2000;111:1646-53.

50 Bittigau $\mathbf{P}$, Sifringer $M$, lkonomidou $C$, et al. Antiepileptic drugs and apoptosis in the developing brain. Proc Natl Acad Sci USA 2002;99:15089-94 (Ann NY Acad Sci 2003;993:103-4). 